\section{Check for updates}

Cite this: Mater. Adv., 2021, 2,5580

Received 20th April 2021, Accepted 15th July 2021

DOI: 10.1039/d1ma00365h

rsc.li/materials-advances

\title{
The journey of PDMS-based nanocomposites for EMI shielding applications: from bench to translational research
}

\author{
Devansh Sharma and Suryasarathi Bose (D) *
}

\begin{abstract}
The advancement in the field of electronics has allowed the miniaturization of electronic devices. Also, lightweight devices have become an integral part of our lives, especially concerning wearable gadgets. In this regard, researchers are exploring polymer nanocomposites as a potential candidate due to their inherent advantages over traditional metals for shielding electromagnetic radiation. In this journey, many polymers, ranging from thermoplastic/thermoset to intrinsically conducting polymers, were explored. Although few reviews have been published in this field, a comprehensive study on PDMS-based shielding materials did not receive much attention. However, its use in electronics has increased significantly in the recent past, especially in biomedical devices. In the last decade, researchers have explored PDMS for making composites, coating materials, and foam-like structures. In this review article, the journey of PDMS-based shielding materials has been highlighted alongside the potential applications targeted and the underlying mechanism of shielding. This comprehensive review focuses on the crucial role of functional nanoparticles that render PDMS composites conducting and make them likely candidates for EMI shielding applications. The importance of cure-kinetics and processing of PDMSbased composites is stressed here as it decides final applications such as flexible gaskets to block radio leakage to reinforced sheets for structural applications.
\end{abstract}

\section{Introduction}

In recent years, many researchers have focused on miniaturizing electronic devices for different applications including medical devices and electronics. ${ }^{1}$ These devices generate (electromagnetic) EM pollution in the ambient atmosphere. Thus, they can affect the working of nearby devices. Therefore, we need to protect the devices from the surrounding EM pollution. Although metals prove to be an efficient EM shields, as they usually reflect the incoming radiation to the ambient atmosphere but they are also prone to corrosion. Thus, researchers moved towards polymerbased composites for designing lightweight, easy to integrate and adapt shielding materials for EM waves.

In a quest to design lightweight, easy to process, integrate, and adapt with the current process lines, researchers have explored thermosets, thermoplastics, and rubber for preparing various functional composites. ${ }^{2,3}$ They have also explored blends of two polymers as they provide the advantage offered by individual components. ${ }^{4}$ Also, one can achieve better EMI shielding by controlling the dispersion state of nanoparticles in the blend. ${ }^{5}$ Many reviews have already discussed the role of

Department of Materials Engineering, Indian Institute of Science,

Bangalore 560012, India. E-mail: sbose@iisc.ac.in polymer nanocomposites in EMI shielding, ${ }^{6,7}$ although the use of PDMS in EMI shielding applications has not received much attention. In Fig. 1, we represent the use of various types of PDMS-based shielding materials.

PDMS, since its discovery by FS kipping in 1901, has been used in various applications such as microfluidic, ${ }^{8}$ oil separation, hydrophobicity, sensors, electromechanical devices, ${ }^{9-12}$ actuators, and sound absorbers ${ }^{13}$ because of its versatile nature. In recent years, many researchers are trying to develop flexible electronic

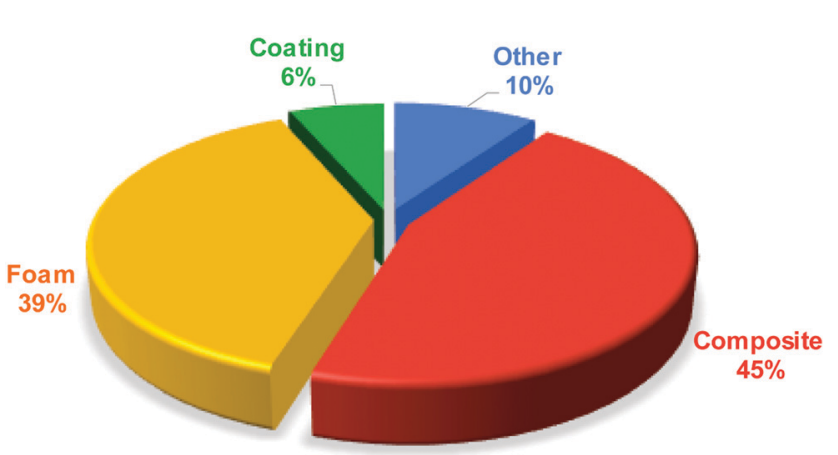

Fig. 1 Percentage-wise representation of various forms of EM shields (based on the available literature in the last decade). 
skin using PDMS. ${ }^{14}$ This review highlights the journey of PDMSbased EMI shielding materials in the last decade. This article is divided into three sections based on the various forms of PDMS that are currently being used, such as (a) foam-like structure, (b) coatings, and (c) composites, as depicted in Fig. 1.

Under the foam category, we have considered the composite where a porous structure is used as a filler and PDMS is infiltrated such that the porosity is maintained. Secondly, PDMS is also used as a coating material for making hydrophobic surfaces and hence, finds application in making hydrophobic EMI shielding materials. Lastly, PDMS based composites for EMI shielding applications have been discussed where PDMS is used as a matrix with some filler. Also, all PDMS-based EM shielding research works are tabulated in Table 1.

\section{Mechanism of shielding in general}

\subsection{EM matter interaction}

The incoming EM waves can undergo absorption, reflection, and transmission after interacting with the sample, as depicted

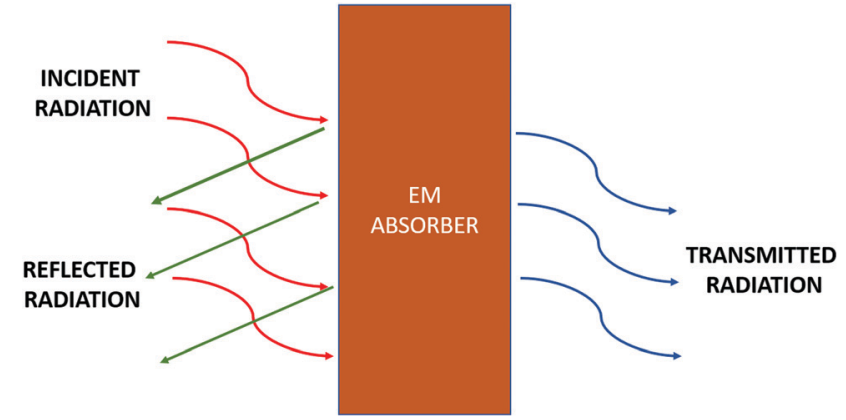

Fig. 2 Interaction of incoming EM radiation with the shield.

in Fig. 2. The mode of interaction majorly depends upon the nature of the material. In general, magnetic, dielectric, or conducting material plays a vital role in EMI shielding. The incoming EM waves interact in different ways and result in the following losses.

2.1.1 EM interaction with conducting materials. Most conductors, like metals, have loosely bound electrons; thus, they cancel the electric field inside the metals. Therefore, when

Table 1 Summary of all the PDMS-based nanocomposites used for EMI shielding

\begin{tabular}{|c|c|c|c|c|c|c|}
\hline S. no. & Filler & $\mathrm{SE} / \mathrm{RL}$ and SSE & $\begin{array}{l}\text { Thickness } \\
(\mathrm{mm})\end{array}$ & \% Loading & Type & Frequency \\
\hline 1. & MXene $^{23}$ & $\mathrm{SE}=70.5 \mathrm{~dB}$ & $2 \mathrm{~mm}$ & $6.1 \mathrm{wt} \%$ & Foam & X-band \\
\hline 2. & $\mathrm{Fe}_{3} \mathrm{O}_{4}$ intercalated MXene and graphene ${ }^{24}$ & $\begin{array}{l}\mathrm{SE}=80 \mathrm{~dB} \\
\mathrm{SE}=77 \mathrm{~dB}\end{array}$ & $1 \mathrm{~mm}$ & 11.35 wt\% $\mathrm{Fe}_{3} \mathrm{O}_{4} @$ MXene & Foam & $\begin{array}{l}\text { X-band } \\
\text { K-band }\end{array}$ \\
\hline 3. & MWCNT and $\mathrm{GO}^{25}$ & $\mathrm{SE}=49 \mathrm{~dB}$ & $T=2.1 \mathrm{~mm}$ & $\begin{array}{l}\mathrm{GO}-100 \mathrm{mg} \\
\mathrm{MWCNT}-41.3 \% \text { to } 91.4 \%\end{array}$ & Foam & $\mathrm{X}$-band \\
\hline 4. & Iron nanoparticles and $\mathrm{MWCNT}^{26}$ & $\mathrm{SE}=48 \mathrm{~dB}$ & $T=1 \mathrm{~mm}$ & $\operatorname{MWCNT}(0,41.3,64.4,84.2,91.2 \mathrm{wt} \%)$ & Foam & $\mathrm{X}$-band \\
\hline 5. & $\mathrm{MWCNT}^{27^{+}}$ & $\mathrm{SE}=46 \mathrm{~dB}$ & $T=2 \mathrm{~mm}$ & $\mathrm{Fe}-13 \mathrm{wt} \%$ & Foam & $\mathrm{X}$-band \\
\hline 6. & Graphite foam ${ }^{28}$ & $\mathrm{SE}=36.1 \mathrm{~dB}$ & $T=4.3 \mathrm{~mm}$ & $1 \mathrm{wt} \% \mathrm{CNT}$ & Foam & $8.2-18 \mathrm{GHz}$ \\
\hline 7. & Carbon nanowire (CNW)/graphene ${ }^{29}$ & $\mathrm{SE}=36 \mathrm{~dB}$ & $T=1.6 \mathrm{~mm}$ & $\mathrm{GF}-15.9 \%$ to $31.7 \%$ & Foam & $\mathrm{X}$-band \\
\hline 8. & $\mathrm{rGO} / \mathrm{ZnO}$ (nanorods) ${ }^{30}$ & $\mathrm{SE}=27.8 \mathrm{~dB}$ & $T=4.8 \mathrm{~mm}$ & $\begin{array}{l}\mathrm{rGO}-0.8 \mathrm{mg} \mathrm{ml}^{-1} \\
\mathrm{rGO} / \mathrm{ZnO}-3.3 \mathrm{wt}^{2} \%\end{array}$ & Foam & X-band \\
\hline 9. & GO aerogel film/ZnO $\mathrm{Zn}^{31}$ & $\mathrm{SE}=43 \mathrm{~dB}$ & $T=1.5 \mathrm{~mm}$ & $\mathrm{GO}-\left(0.6,0.8,1,1.3 \mathrm{mg} \mathrm{ml}^{-1}\right)$ & Foam & $\mathrm{X}$-band \\
\hline 10. & Quartz fiber cloth/MWCNT ${ }^{14}$ & $\mathrm{SE}=20 \mathrm{~dB}$ & - & $\mathrm{rGO} / \mathrm{ZnO}-3.3 \mathrm{wt} \%$ and $2 \mathrm{wt} \% \mathrm{MWCNT}$ & Foam & $\mathrm{X}$-band \\
\hline 11. & Graphene foam ${ }^{32}$ & $\mathrm{SE}=30 \mathrm{~dB}$ & $T=1 \mathrm{~mm}$ & $\mathrm{ZnO}-21.7 \mathrm{wt} \%$ & Foam & $\begin{array}{l}300 \mathrm{MHz}- \\
1.5 \mathrm{GHz}\end{array}$ \\
\hline 12. & $\mathrm{Fe}_{3} \mathrm{O}_{4}$ and MWCNT over cotton fabric ${ }^{33}$ & $\mathrm{SE}=84.5 \mathrm{~dB}$ & $T=0.96 \mathrm{~mm}$ & MWCNT - 0.7-2 wt\% & Coating & $\mathrm{X}$-band \\
\hline 13. & Ag coated PP fabric with PDMS layer ${ }^{34}$ & $\mathrm{SE}=71.2 \mathrm{~dB}$ & $T=1.3 \mathrm{~mm}$ & $\mathrm{Ag}<0.8 \mathrm{wt} \%$ & Coating & X-band \\
\hline 14. & Flaky iron and PDMS ${ }^{35}$ & $\begin{array}{l}\mathrm{RL}=-53.3 \mathrm{~dB} \\
\text { at } 4.3 \mathrm{GHz}\end{array}$ & $T=4.3 \mathrm{~mm}$ & $20 \mathrm{wt} \% \mathrm{Fe}$ & Composite & $2-18 \mathrm{GHz}$ \\
\hline 15. & MWCNT $^{36}$ & $\mathrm{SE} \approx-28 \mathrm{~dB}$ & $T=0.9 \mathrm{~mm}$ & Ag coating $(5-50 \%)$ & Composite & $12-18 \mathrm{GHz}$ \\
\hline 16. & Cotton fabric and MWCNT $^{37}$ & $\mathrm{SE}=41 \mathrm{~dB}$ & $T=1.2 \mathrm{~mm}$ & $20 \mathrm{wt} \% \mathrm{Fe}$ & Composite & $\mathrm{X}$-band \\
\hline 17. & MWCNT/graphene ${ }^{38}$ & $\mathrm{SE}=68 \mathrm{~dB}$ & $T=1 \mathrm{~mm}$ & $3 \mathrm{wt} \%$ MWCNT & Composite & X-band \\
\hline 18. & Carbon black and $\mathrm{rGO}^{39}$ & $\mathrm{SE}=28 \mathrm{~dB}$ & $T=2 \mathrm{~mm}$ & CTF - 15 vol\% & Composite & $8-18 \mathrm{GHz}$ \\
\hline 19. & GaInSn with PDMS ${ }^{40}$ & $\begin{array}{l}\mathrm{RL}=-19.3 \mathrm{~dB} \\
\text { at } 14.8 \mathrm{GHz}\end{array}$ & $T=2 \mathrm{~mm}$ & MWCNT - 3 vol\% & Composite & $2-18 \mathrm{GHz}$ \\
\hline 20. & $\mathrm{BaTiO}_{3}^{41}$ & $\mathrm{SE}=11 \mathrm{~dB}$ & $200-250 \mu \mathrm{m}$ & MWCNT - 2 wt $\%$ & Composite & X-band \\
\hline 21. & $\mathrm{Gd}_{5} \mathrm{Si}_{4}$ and $\mathrm{PDMS}^{42}$ & $\mathrm{SE} \sim 69 \mathrm{~dB}$ & $T=1 \mathrm{~mm}$ & $\mathrm{CB}-2,5,7,10,15,17,20 \mathrm{wt} \%$ & Composite & $(12.4-18 \mathrm{GHz})$ \\
\hline 22. & $\mathrm{~N}$-doped graphene ${ }^{43}$ & $\mathrm{SE}=58.6 \mathrm{~dB}$ & $T=9.35 \mu \mathrm{m}$ & rGO - $10,15,17$ wt $\%$ & Composite & $\mathrm{X}$-band \\
\hline 23. & Silver nanowire/rGO ${ }^{44}$ & $\mathrm{SE}=34.1 \mathrm{~dB}$ & $T=2 \mathrm{~mm}$ & GaInSn : PDMS $3.3: 2$ and $3.3: 4$ & Composite & $\mathrm{X}$-band \\
\hline 24. & $\mathrm{Fe}_{3} \mathrm{O}_{4}$ over $\mathrm{MWCNT}^{45}$ & $\begin{array}{l}\mathrm{RL}=41.3 \mathrm{~dB} \\
\text { at } 14 \mathrm{GHz}\end{array}$ & $T=2 \mathrm{~mm}$ & BaTiO3 - 15 wt\% & Composite & $2-18 \mathrm{GHz}$ \\
\hline 25. & Graphene $^{46}$ & $\mathrm{SE}=54 \mathrm{~dB}$ & $T=2 \mathrm{~mm}$ & Gd5Si4 - 40 wt $\%$ & Composite & $\mathrm{X}$-band \\
\hline 26. & rGO- $\mathrm{Fe}_{3} \mathrm{O}_{4}$ grown over $\mathrm{MWCNT}^{47}$ & $\begin{array}{l}\mathrm{RL}=-50.5 \mathrm{~dB} \\
\text { at } 16.3 \mathrm{GHz}\end{array}$ & $T=1.42 \mathrm{~mm}$ & $\mathrm{Fe}_{3} \mathrm{O}_{4}-4,6,6,5$ and $5 \times 10^{-5} \mathrm{~g} \mathrm{~cm}^{-2}$ & Composite & $2-18 \mathrm{GHz}$ \\
\hline 27. & $\mathrm{rGO} / \mathrm{SWCNT}{ }^{48}$ & $\mathrm{SE}=31 \mathrm{~dB}$ & $T=2 \mathrm{~mm}$ & AgNWs - 0.43 wt $\%$ & Composite & $\mathrm{X}$-band \\
\hline 28. & $\mathrm{Fe}_{3} \mathrm{O}_{4}$ embedded hollow $\mathrm{CNF}^{49}$ & $\mathrm{RL}=-25 \mathrm{~dB}$ & $T=7.5 \mathrm{~mm}$ & rGO - 0.33 wt $\%$ & Composite & $2-18 \mathrm{GHz}$ \\
\hline 29. & $\mathrm{Ag}$ and $\mathrm{Fe}_{3} \mathrm{O}_{4}{ }^{10}$ & $\mathrm{SE}=56.1 \mathrm{~dB}$ & $T=7.5 \mathrm{~mm}$ & $\mathrm{Ag}-5 \%, 10 \%, 15 \%, 20 \%, 25 \%$ & Other & $\mathrm{X}$-band \\
\hline 30. & SiOC fibers ${ }^{50}$ & $\mathrm{RC}=36 \mathrm{~dB}$ & $T=2.5 \mathrm{~mm}$ & Graphene - 3.07 wt $\%$ & Other & $\mathrm{X}$-band \\
\hline 31. & $\mathrm{Fe}_{3} \mathrm{O}_{4}$ coated carbon fiber ${ }^{51}$ & $\mathrm{SE}=23 \mathrm{~dB}$ & $T=0.7 \mathrm{~mm}$ & With $0.2,0.3,0.4,0.5$, and $0.06 \mathrm{M} \mathrm{FeCl}_{3}$ & Other & $\mathrm{X}$-band \\
\hline
\end{tabular}


the incoming EM waves interact with the metal, they tend to move the electrons. These electrons move to generate a cancelling field; thus, metals tend to reflect the EM radiation. ${ }^{15}$

Apart from metals, the loss in other conducting materials like MWCNT and other nanowires is majorly due to conduction loss. Therefore, the incoming EM radiation tends to move the electron inside these materials, resulting in loss due to conduction. For conduction loss, the particles should form a closed percolating network for the conduction of charges under the impact of EM waves. To get insights into the impact of conductivity on EMI shielding, generally, AC conductivity response with varying frequency is studied as per Jonscher's power law given below. ${ }^{16}$

$$
\sigma_{\mathrm{ac}}=\sigma(0)+\sigma(\omega)=\sigma_{\mathrm{o}}+A \omega^{n}
$$

According to the law, the AC conductivity in a complex system like composite can be considered as the combination of resistors and capacitors. At low frequency, only resistive pathways show conductivity through tunnelling. As the frequency increases, the capacitive pathways become conductive in nature. Therefore, conductivity increases through hopping.

Thus, the law gives insights into the charge transport mechanism in a system. The value of exponent $n$ can vary from 0 to 1 and is dependent on temperature and frequency. It represents the capacitive pathways inside the system. With increasing conductive pathways inside the system, the value of $n$ decreases.

Nanomaterials with elongated geometry (like chains, rods, and tubular shapes) tend to form percolating networks at low concentrations and are favourable for EMI shielding applications.

2.1.2 EM interaction with dielectric materials. When EM waves interact with the dielectric material, they can result in loss due to multiple factors. The losses can be due to the generation of dipoles on account of the interaction between the oscillating electric field and dipoles within the material. ${ }^{17}$

2.1.3 EM interaction with magnetic materials. Magnetic materials show significant loss due to the absorption of EM waves. The incoming EM wave interacts with magnetic domains and tries to orient them in the applied field direction. With changing magnetic fields, these domains oscillate, providing loss due to resonance of the domain wall. ${ }^{18}$ Also, there is a loss due to the eddy current generation because of the interaction between the electric and the magnetic material. ${ }^{19,20}$ But the magnetic losses become insignificant at higher frequencies as their permeability decreases. Thus, magnetic loss decreases drastically at higher frequencies as defined by Snoek's limit. ${ }^{21}$

\subsection{Measurement of EMI shielding}

The performance of EM shields to attenuate the incoming EM waves can be expressed using shielding effectiveness and reflection loss.

2.2.1 Shielding effectiveness (SE). Shielding effectiveness is defined as the logarithmic ratio of incident wave $\left(P_{\mathrm{i}}\right)$ power to transmitted wave $\left(P_{\mathrm{t}}\right)$. It is expressed in terms of $\mathrm{dB}$.

$$
\mathrm{SE}_{\mathrm{T}}(\mathrm{dB})=-10 \log \left(\frac{P_{i}}{P_{t}}\right)=\mathrm{SE}_{\mathrm{A}}+\mathrm{SE}_{\mathrm{R}}+\mathrm{SE}_{\mathrm{MR}}
$$

where $\mathrm{SE}_{\mathrm{T}}$ refers to total shielding effectiveness, $\mathrm{SE}_{\mathrm{A}}$ refers to shielding effectiveness due to absorption, $\mathrm{SE}_{\mathrm{R}}$ refers to shielding effectiveness due to reflection, and $\mathrm{SE}_{\mathrm{MR}}$ refers to shielding effectiveness due to multiple reflections.

$\mathrm{SE}_{\mathrm{A}}, \mathrm{SE}_{\mathrm{R}}, \mathrm{SE}_{\mathrm{MR}}$ can be theoretically calculated using the following relations,

$$
\begin{gathered}
\mathrm{SE}_{\mathrm{A}}(\mathrm{dB})=-8.68 d \sqrt{\frac{\omega \sigma \mu_{\mathrm{r}}}{2}} \\
\mathrm{SE}_{\mathrm{R}}(\mathrm{dB})=-10 \log \frac{\sigma}{16 \omega \varepsilon_{\mathrm{o}} \mu_{\mathrm{r}}} \\
\mathrm{SE}_{\mathrm{MR}}(\mathrm{dB})=20 \log \left|\left(1-10^{-\frac{\mathrm{SE}_{\mathrm{A}}}{10}}\right)\right|
\end{gathered}
$$

But experimentally, we can calculate shielding effectiveness in terms of $S$-parameters as follows:

$$
\begin{gathered}
\mathrm{SE}_{\mathrm{T}}(\mathrm{dB})=\left|S_{12}\right|^{2} \\
\mathrm{SE}_{\mathrm{R}}(\mathrm{dB})=\left|S_{11}\right|^{2} \\
\mathrm{SE}_{\mathrm{A}}(\mathrm{dB})=\mathrm{SE}_{\mathrm{T}}-\mathrm{SE}_{\mathrm{A}}
\end{gathered}
$$

where $\omega$ is the angular frequency $(\omega=2 \pi f)$ and $f$ is the frequency of oscillation. $\mu$ is the magnetic permeability, and $\varepsilon$ is the electrical permittivity and $d$ is the thickness of the material.

2.2.2 Reflection loss. Also, for materials with magnetic permeability $(\mu)$ and permittivity $(\varepsilon)$, the shielding efficiency can be expressed in terms of the reflection loss $(\mathrm{RL})$ or reflection coefficient (RC).

$$
\mathrm{RL} \text { or } \mathrm{RC}=20 \log \left|\frac{Z_{\text {in }}-Z_{\mathrm{o}}}{Z_{\text {in }}+Z_{\mathrm{o}}}\right|
$$

where $Z_{\mathrm{o}}$ is the impedance for free space $\left(Z_{\mathrm{o}}=377 \Omega\right)$, and $Z_{\text {in }}$ is input impedance, which is calculated as follows:

$$
Z_{\text {in }}=Z_{\mathrm{o}} \sqrt{\frac{\mu_{\mathrm{r}}}{\varepsilon_{\mathrm{r}}}} \tanh \left\{j\left(\frac{2 \pi f d}{c}\right) \sqrt{\mu_{\mathrm{r}} \varepsilon_{\mathrm{r}}}\right\}
$$

where $c$ refers to the speed of light.

\section{State of the Art}

\subsection{PDMS based foam-like structures}

Dongyi et al. $^{22}$ prepared 3D graphene foam using CVD. They used nickel foam as a template over which graphene was grown. This 3D porous network was further infiltrated with PDMS under the vacuum. The prepared composite showed superior conductivity of $6100 \mathrm{~S} \mathrm{~m}^{-1}$ with only $1.2 \mathrm{wt} \%$ graphene. The prepared composite showed very high EMI shielding of around $40 \mathrm{~dB}$ for a $0.25 \mathrm{~mm}$ thick sample.

$\mathrm{Wu}$ et $a .^{23}$ synthesized foam-like structures using two MXene. They fabricated MXene foam using sodium alginate. 
Thus, the prepared conductive foam was coated with a thin layer of PDMS. Therefore, the prepared foam-like structure showed high conductivity of $2211 \mathrm{~S} \mathrm{~cm}^{-1}$ and high average shielding efficiency (SE) of $70.5 \mathrm{~dB}$. After 500 compression cycles, the composite with $6.1 \mathrm{wt} \%$ MXene showed an SE of 48.2 dB.

Nguyen et $a .^{24}$ prepared nanocomposites using ferrite $\left(\mathrm{Fe}_{3} \mathrm{O}_{4}\right)$ particles intercalated MXene and graphene composite for multifunctional EMI shielding, as shown in Fig. 3. They dispersed MXene in water with different concentrations (1\%, $3 \%$, and $5 \%$ ), followed by the addition of $\mathrm{Fe}_{3} \mathrm{O}_{4}$ nanoparticles (3 wt \%). Then, the formed solution was sonicated for $6 \mathrm{~h}$ to form a homogeneous dispersion. Graphene foam (GF) was developed using $\mathrm{CVD}$ on a $\mathrm{Ni}$ substrate followed by $\mathrm{Fe}_{3} \mathrm{O}_{4}$ @$\mathrm{TiC}_{2} \mathrm{~T}_{x}$ in nickel foam. After the addition of $\mathrm{Fe}_{3} \mathrm{O}_{4}$ particles, PDMS was introduced and cured. Finally, Ni was etched out using $\mathrm{FeCl}_{3}$ solution. They achieved a high EM shielding value for a $1 \mathrm{~mm}$ thick sample (SE= $80 \mathrm{~dB}$ in X-band and $77 \mathrm{~dB}$ in Kaband) with $11.35 \mathrm{wt} \% \mathrm{Fe}_{3} \mathrm{O}_{4} @ \mathrm{TiC}_{2} \mathrm{~T}_{x}$ particles.

Kong et al. ${ }^{25}$ synthesized high EM wave absorbing material using MWCNT and reduced graphene oxide (rGO). In the process, they first prepared a graphene oxide (GO) solution containing cobalt acetate $\left(2 \mathrm{mg} \mathrm{ml}^{-1}\right)$. The solution was freezedried for $24 \mathrm{~h}$. Thus, obtained foam-like structure was further used to grow MWCNT using CVD. Hence, the prepared foam was coated with PDMS. The obtained foam shows an SE value reaching $49 \mathrm{~dB}$ for a $3.1 \mathrm{~mm}$ thick sample.

$\mathrm{Yu}$ et $a .^{26}$ prepared $\mathrm{Fe}$ decorated porous carbon and graphene foam. They prepared a Fe nanoparticle/CNT network by carbonizing Fe(acac) $)_{3}$ decorated zeolitic imidazole framework-8 (ZIF-8) at $950{ }^{\circ} \mathrm{C}$ for 10 min under Ar atmosphere. The prepared composite showed shielding effectiveness $(\mathrm{SE} \sim 48 \mathrm{~dB})$ and specific shielding effectiveness as $347.8 \mathrm{~dB} \mathrm{~cm}^{3} \mathrm{~g}^{-1}$.
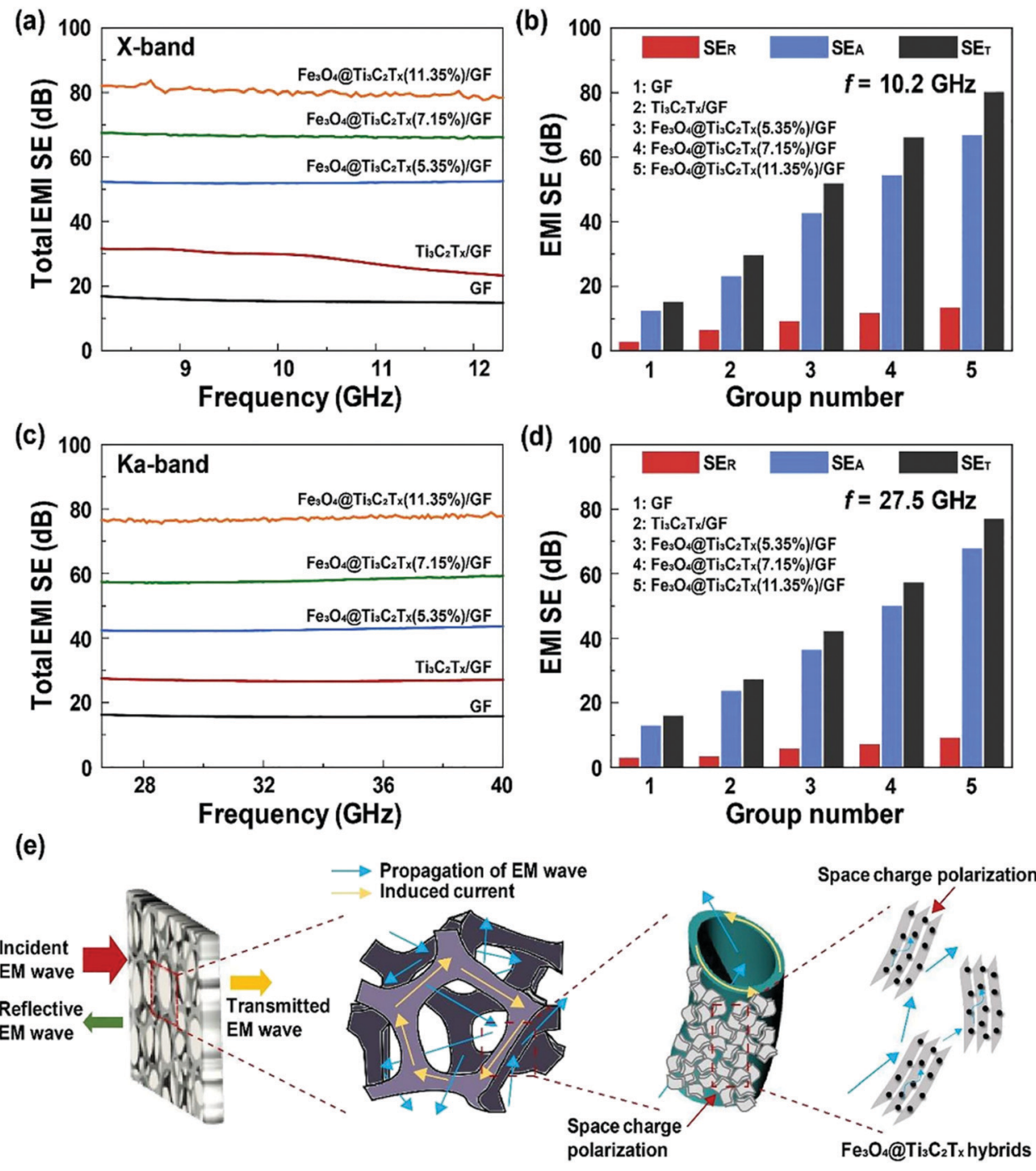

Fig. 3 (a and c) Total EMI shielding of prepared samples in X-and K-bands, respectively. (b and d) shows $\mathrm{SE}_{\mathrm{A}}$, $\mathrm{SE}_{\mathrm{R}}$, and $\mathrm{SE}_{\mathrm{T}}$ for different foams at $10.2 \mathrm{GHz}$ and $27.5 \mathrm{GHz}$, respectively. (e) Mechanism of EM wave interaction with the foam. [Reprinted (adapted) with permission from (Chem. Eng. J., 2020, 393, 124608). Copyright (2020) Elsevier.] 
Lu et $a .^{27}$ made a flexible CNT/PDMS sponge with a thickness of $2 \mathrm{~mm}$. They prepared a CNT sponge using the CVD method. They infiltrated PDMS under negative pressure for $30 \mathrm{~min}$ followed by curing at $55{ }^{\circ} \mathrm{C}$ for $2 \mathrm{~h}$. Thus, the prepared composite showed SE 46.3 dB with only $1 \mathrm{wt} \% \mathrm{CNT}$ content. PDMS was infiltrated into the CNT sponge through vacuum impregnation.

$\mathrm{Li}$ et $a .^{28}$ obtained thin layer graphite foam (GF) with controlled density (27.2-69.2 $\left.\mathrm{mg} \mathrm{cm}^{-3}\right)$ after carbonizing polyacrylonitrile foam as represented in Fig. 4. This is followed by the addition of PDMS, resulting in a porous GF@PDMS structure with varying GF concentrations from $15.9 \%$ to $31.7 \%$. The prepared composite showed high conductivity (up to $34.3 \mathrm{~S} \mathrm{~cm}^{-1}$ ) and low thermal conductivity $\left(0.062-0.076 \mathrm{Wm}^{-1} \mathrm{~K}^{-1)}\right.$, and high EMI SE (up to $36.1 \mathrm{~dB}$ ) for a $4.5 \mathrm{~mm}$ thick sample over the frequency range $8.2-18 \mathrm{GHz}$.

Kong et $a l .{ }^{29}$ prepared covalently bonded carbon nanowire and graphene (CNWs/graphene) architecture using a bioinspired approach from polydopamine as an interface buffer fabrication of 3D macroscopic CNWs/G sponge. A thin layer of PDMS was coated by dipping foam into PDMS and curing at $150{ }^{\circ} \mathrm{C}$ for $1 \mathrm{~h}$. The sponge showed excellent EMI shielding ability of (SE $36 \mathrm{~dB}$ ) in the X-band.

Song et $a .^{30}$ used three-dimensional rGO foam modified with zinc oxide ( $\mathrm{ZnO}$ NWs) to suppress EM waves. In a typical process, they first prepared rGO foam using the freeze-drying

(a)
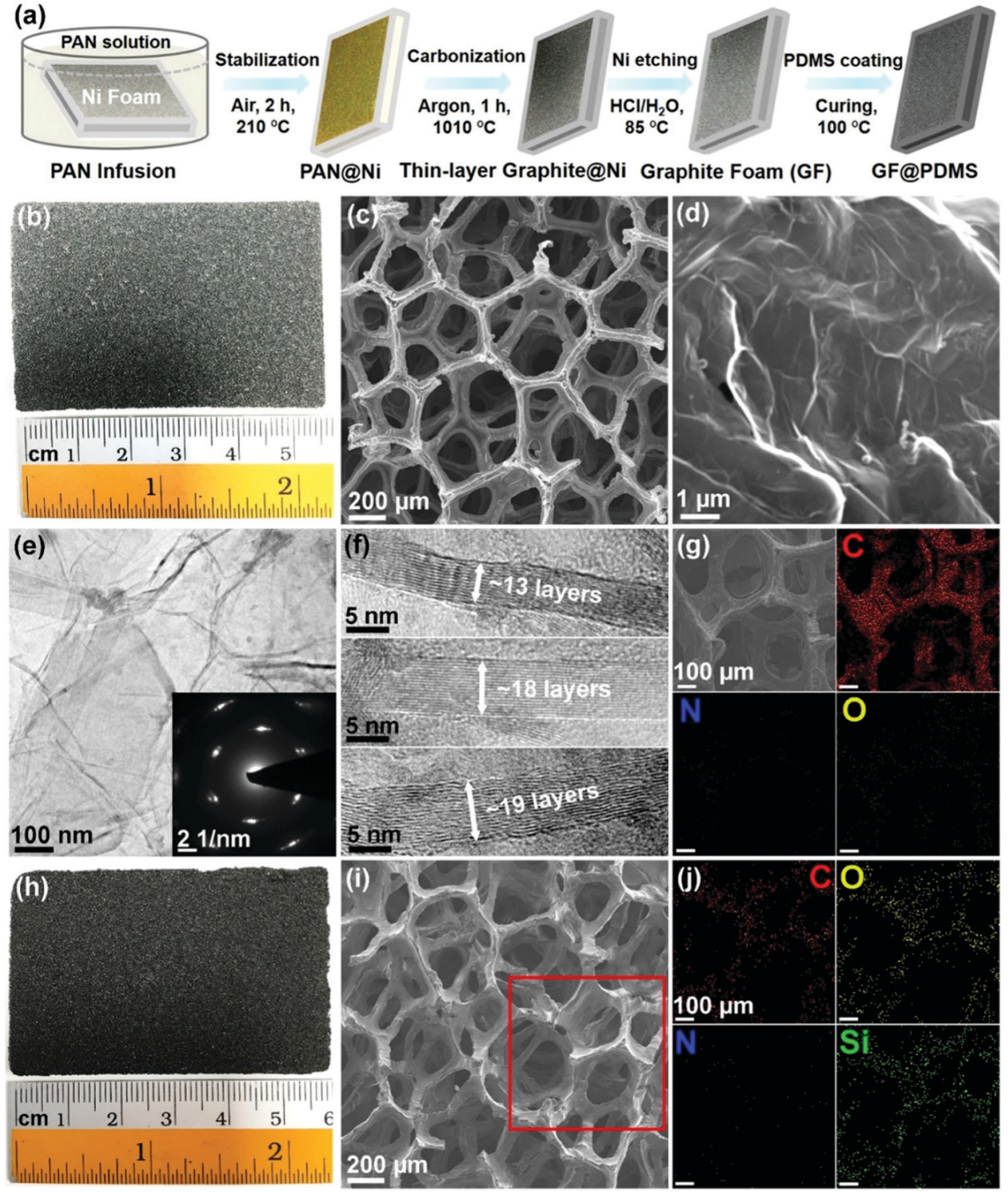

Fig. 4 Preparation process, morphology, and microstructure of GF27.2 and 15.9\% GF@PDMS. (a) Schematic illustration of the preparation process. Optical (b), SEM (c and d), and TEM (e and f) images of GF-27.2 and the corresponding SEM/EDX elemental mapping (g) of $C, O$, and N elements. Inset of (e) shows the SAED image of GF-27.2. Optical (h) and SEM images (i) of 15.9\% GF@PDMS and the corresponding SEM/EDX elemental mapping (j) of C, O, $\mathrm{N}$, and Si elements for the selected area in (i). [Reprinted (adapted) with permission from (ACS Appl. Mater. Interfaces, 2018, 10(48), 41707-41716). Copyright (2018) American Chemical Society.]. 
method, followed by the synthesis of $\mathrm{ZnO}$ nanowires using seed-mediated growth. They infiltrated PDMS using a vacuum. The porous EMI shield showed minimum $\mathrm{RC}\left(\mathrm{RC}_{\min }=-31.1 \mathrm{~dB}\right)$ for ZnO NWs/RGO foam/PDMS with $0.8 \mathrm{mg} \mathrm{ml}^{-1} \mathrm{RGO}$ at $9.2 \mathrm{GHz}$ for a $5 \mathrm{~mm}$ thick sample.

Han et $a l .{ }^{31}$ synthesized composite film using rGO and zinc by dispersing zinc in an acidic solution of GO. The composite film was dialyzed for $12 \mathrm{~h}$ to remove acidic impurities. The obtained gel was freeze-dried for $36 \mathrm{~h}$ to make the foam-like structure. PDMS was infiltrated, and the sample was cured at $80{ }^{\circ} \mathrm{C}$ for $4 \mathrm{~h}$. For preparing a multilayer stack, several such layers were used in combination. The composite showed SE $23 \mathrm{~dB}$. Also, they claimed that the composite film acts as an absorber and reflector in X-band. For the multilayer structure, they achieved $\mathrm{SE} \sim 47 \mathrm{~dB}$ to $53 \mathrm{~dB}$.

Chen et al. ${ }^{14}$ used quartz fiber cloth (QFC) reinforced MWCNTs-carbon aerogel (QMCA) by chemical route. The prepared gel was freeze-dried to form the final porous structure. The PDMS based composite was made through vacuum infiltration followed by curing at $90{ }^{\circ} \mathrm{C}$ for $30 \mathrm{~min}$. The prepared composite showed EM shielding of SE $\sim 20 \mathrm{~dB}$.

Chen et $a .^{32}$ prepared lightweight graphene foam composites with a density of $0.06 \mathrm{~g} \mathrm{~cm}^{-3}$. In a typical process, they have grown graphene over Ni substrate; after that thin layer of PDMS was coated over the foam. After PDMS coating, Ni was etched out by dipping into $\mathrm{HCl}$ solution for $24 \mathrm{~h}$. The prepared sample shows $\mathrm{SE} \sim 30 \mathrm{~dB}$ and specific shielding effectiveness of $500 \mathrm{~dB} \mathrm{~cm} \mathrm{~g}^{-1}$ in the frequency range (300 MHz-1.5 GHz). The foam composite showed excellent SE even after bending for 10000 cycles.

\subsection{PDMS based coating materials}

Wang et al. ${ }^{33}$ prepared layer-by-layer assembly using $\mathrm{Fe}_{3} \mathrm{O}_{4}$ and MWCNT over the cotton fabric to shield the EM waves. After the deposition of nanoparticles, the fabric was coated with PDMS. The robust EM shielding material showed shielding effectiveness of $\approx 84.5 \mathrm{~dB}$ in $\mathrm{X}$-band with $0.96 \mathrm{~mm}$ thickness and good thermal conductivity.

Luo et al. $^{34}$ developed a self-cleaning composite for EMI shielding application by coating PDMS over PP fabric, as depicted in Fig. 5. They prepared the composite in three steps; firstly, they prepared PDA coating over the PP surface followed by chemically reducing Ag over the PP fabric. The obtained fabric was coated with a PDMS layer to provide hydrophobicity. The prepared composite showed high contact angle of $\sim 152.3^{\circ}$. The coated fabric shows high conductivity of $81.2 \mathrm{~S} \mathrm{~cm}^{-1}$ and $\mathrm{SE} \sim 71.2 \mathrm{~dB}$ (refer Fig. 6).

\subsection{PDMS based nanocomposites}

Zheng et $a l .{ }^{35}$ used flaky iron (F-Fe) (20 wt\% and $28 \mathrm{wt} \%$ ) as a filler to prepare magnetorheological film by mixing $\mathrm{F}-\mathrm{Fe}$ in dimethyl silicone oil as shown in Fig. 7, followed by the addition of silicone rubber (SR). This solution was thoroughly mixed using a mechanical mixer. After this, the solution was vulcanized at $40{ }^{\circ} \mathrm{C}$ for $12 \mathrm{~h}$. For preparing the aligned sample, the sample was cured under a $200 \mathrm{mT}$ magnetic field. They compared the EM shielding performance of the prepared sample with a wax alternative. They got a minimum reflection loss (RL) value of $-53.3 \mathrm{~dB}$ at $4.3 \mathrm{GHz}$ for a $4.3 \mathrm{~mm}$ sample (refer to Fig. 8).

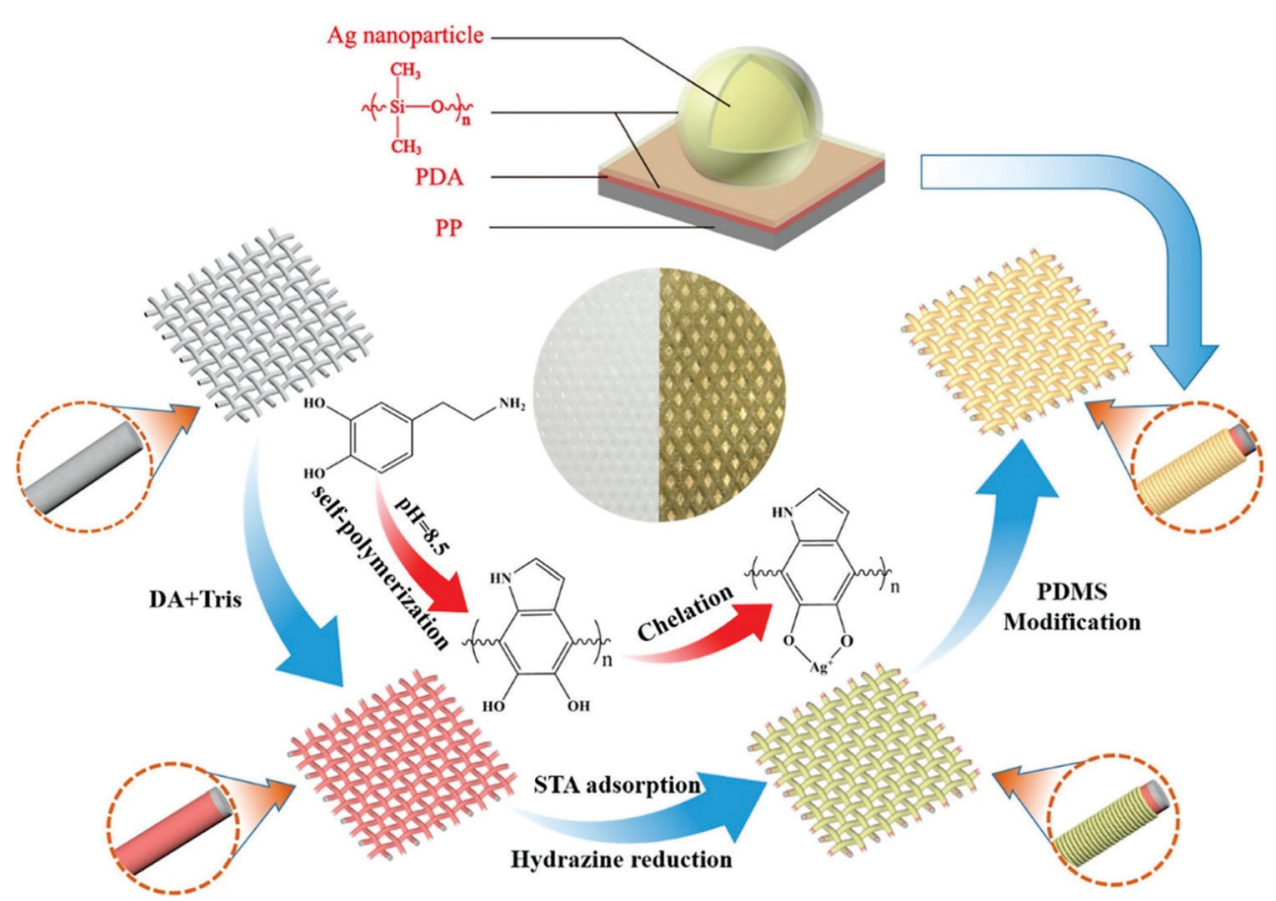

Fig. 5 Schematic for the fabrication of the superhydrophobic and EMI shielding PP/PDA/Ag NPs/PDMS fabric. [Reprinted (adapted) with permission from (ACS Appl. Mater. Interfaces, 2019, 11(11), 10883-10894). Copyright (2019) American Chemical Society.]. 


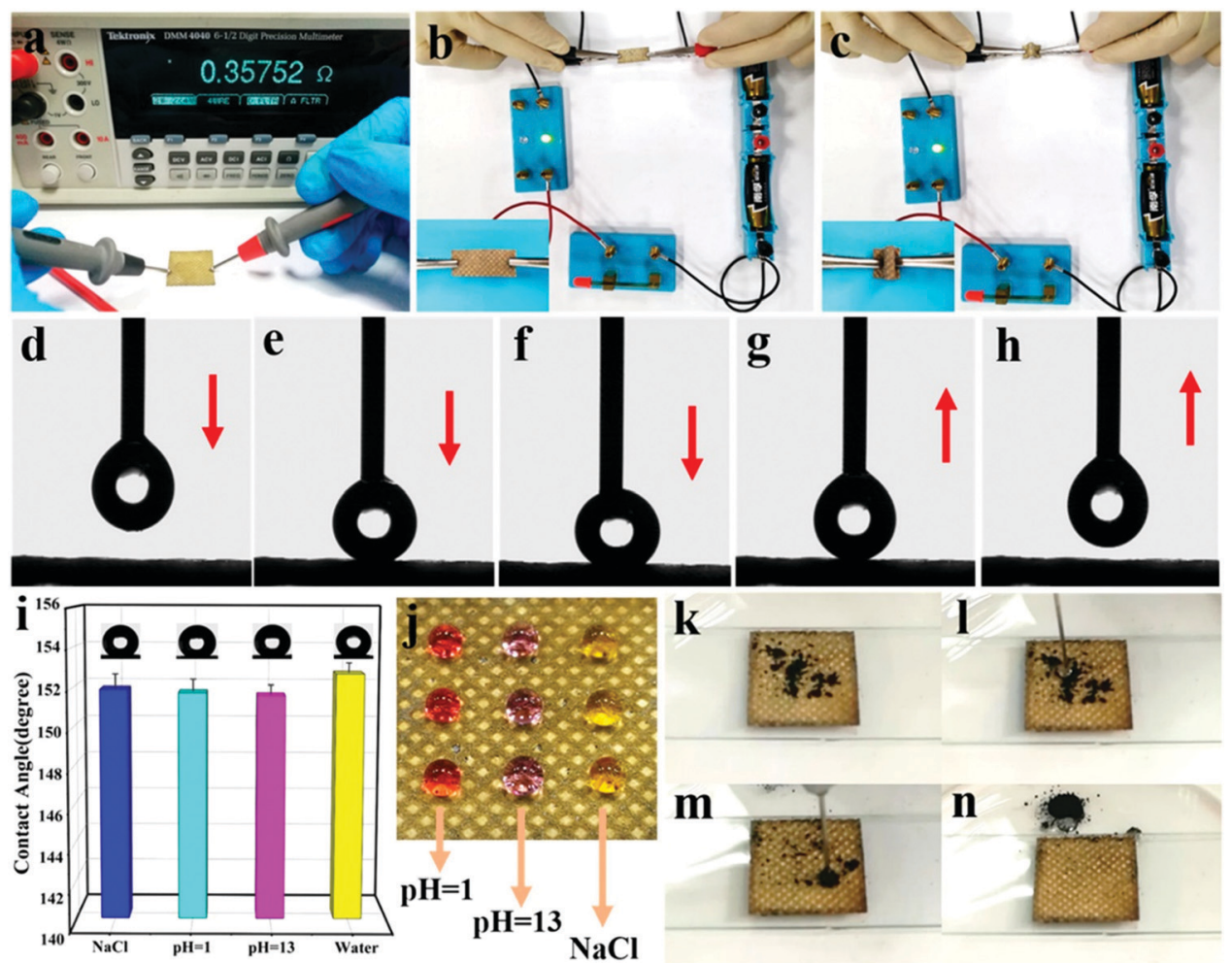

Fig. 6 (a) Photograph showing the surface resistance of the composite fabric (PP/PDA/Ag NPs-25\%/PDMS-40). (b) Digital photo images displaying the composite fabric in a circuit, and (c) the LED light in the circuit maintaining its original brightness during the bending. (d-h) Photographs of contact, press, and departure processes of a $5 \mu \mathrm{l}$ water droplet on the composite fabric surface. (i) CAs of various corrosive solution droplets on the composite surface. (j) Photograph of the liquid droplets of acid (dyed in red), alkali (dyed in pink), and salt (dyed in yellow) solution on the fabric surface. ( $k-n)$ Photographs exhibiting the self-cleaning behavior of the fabric surface. Note that the composite fabric used in all the tests is PP/PDA/AgNPs-25\%/PDMS-40. [Reprinted (adapted) with permission from (ACS Appl. Mater. Interfaces, 2019, 11(11), 10883-10894). Copyright (2019) American Chemical Society.].

(a)

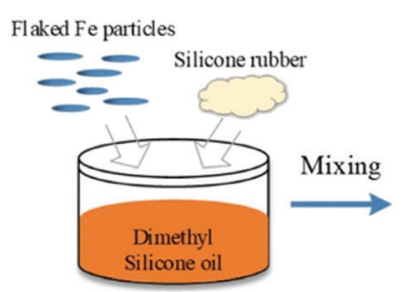

(c)

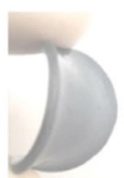

Mechanical Stirring
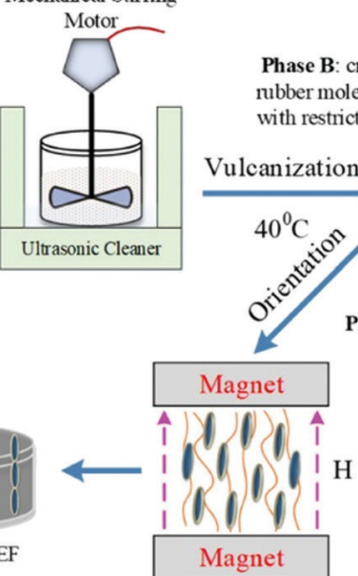

(b)

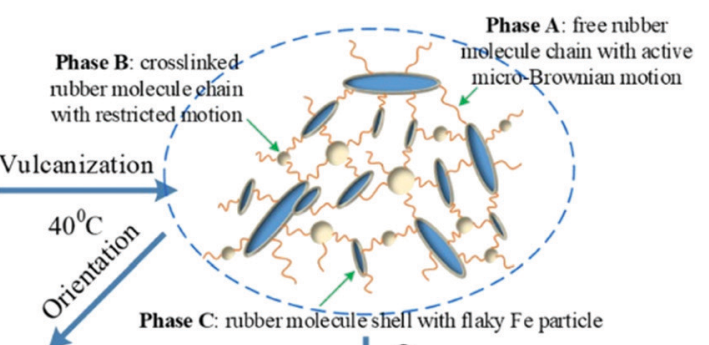

Phase C: rubber molecule shell with flaky Fe particle

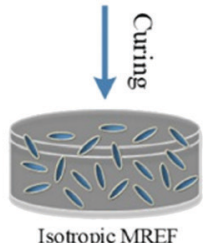

Fig. 7 (a) Physical mixing of flaked Fe particles in silicone rubber using a combination of mechanical stirrer and ultrasonication (b) crosslinking of silicone rubber with the help of crosslinker (c) alignment of flaky Fe nanoparticles with the help of an external magnetic field. [Reprinted (adapted) with permission from (Ind. Eng. Chem. Res. 2020, 59, 8, 3425-3437). Copyright (2020) American Chemical Society.].

Nallabothula et $a l .{ }^{36}$ used two different processes, i.e., spin coating and compression moulding for dispersing MWCNT in PDMS matrix and studied the effect of the processing technique on the state of dispersion and EMI shielding performance of the prepared composite. They further formed a multilayer stack by dispersing $\mathrm{Fe}_{3} \mathrm{O}_{4}$ particles and MWCNT with the optimized 

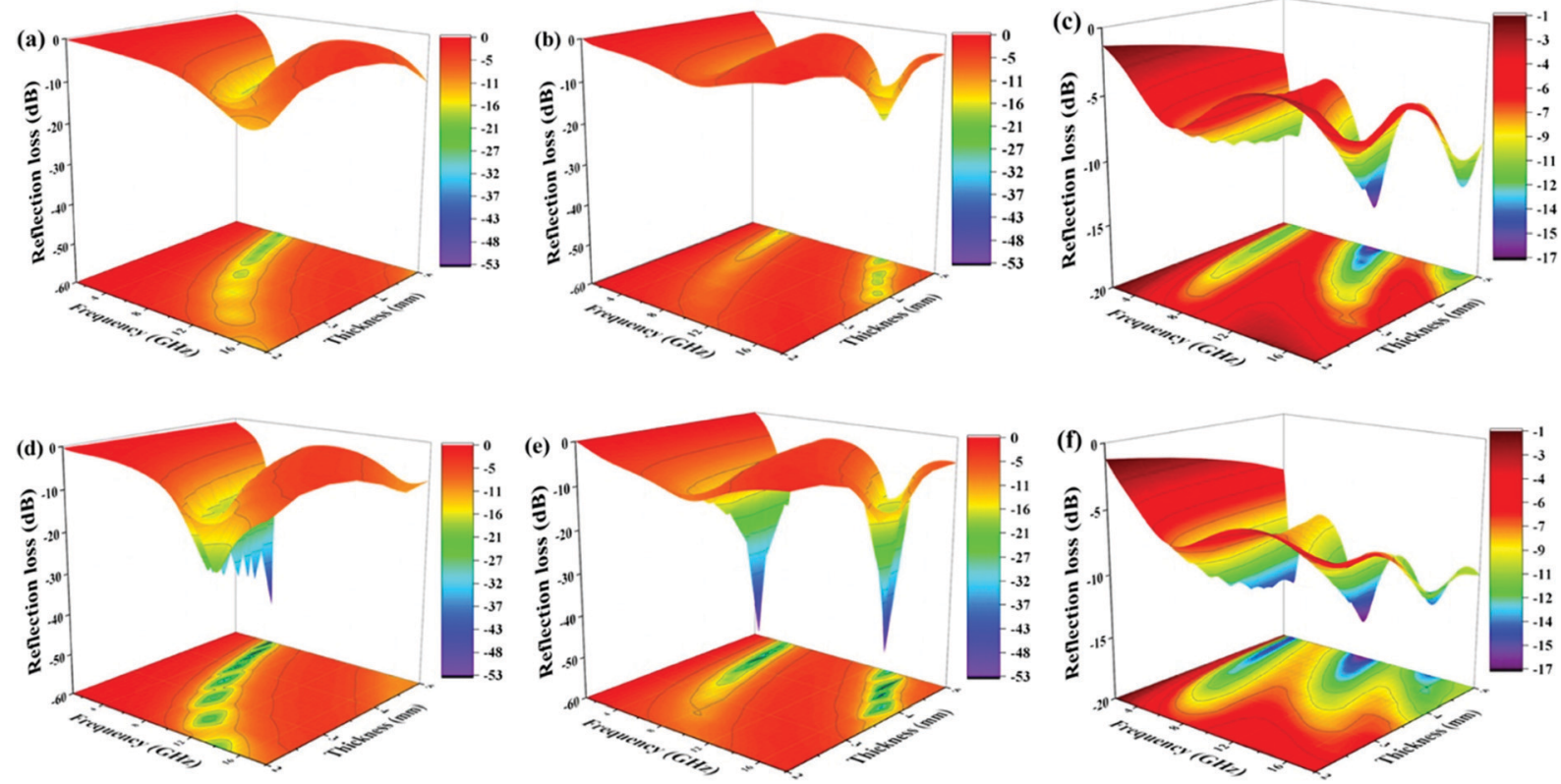

Fig. 8 3D representations of calculated RL values of ( $a$ and d) F-Fe/paraffin, (b and e) I-F-Fe/MREF, and (c and f) A-F-Fe/MREF with 20 and 28 wt\% loadings. [Reprinted (adapted) with permission from (Ind. Eng. Chem. Res., 2020, 59(8), 3425-3437). Copyright (2020) American Chemical Society.]

process. They found that compression moulding results in proper dispersion of MWCNT compared to spin coating. For the multilayer stack, they achieved $\mathrm{SE} \approx-28 \mathrm{~dB}$ for a $0.9 \mathrm{~mm}$ thick sample.

Li $e t a l .{ }^{37}$ used cotton fibres (CTF) in addition to MWCNT to construct multiple interfaces in PDMS-based composite. They dispersed MWCNT in PDMS by ultrasonication in dichloromethane solvent, followed by degassing and post-curing at $80{ }^{\circ} \mathrm{C}$ for $2 \mathrm{~h}$. They found that the EM shielding effectiveness (SE) for the sample with $2 \mathrm{vol} \%$ and $3 \mathrm{vol} \%$ MWCNT increases from $\sim 16 \mathrm{~dB}$ to $\sim 30 \mathrm{~dB}$ and $\sim 20 \mathrm{~dB}$ to $\sim 41 \mathrm{~dB}$ with the addition of $15 \mathrm{wt} \%$ CTF for $1.2 \mathrm{~mm}$ thick sample.

Zhu et $a l .{ }^{38}$ prepared a composite using cake-like flexible MWCNT/graphene and PDMS. In a typical process, they oxidized MWCNT (OCNT) using Hummers' method. Thus, the obtained OCNTs wet cake was freeze-dried and re-grinded. The OCNT/ graphene $(\mathrm{G})$ were dispersed together and filtered using a PTFE membrane, therefore, giving a wet cake-like structure followed by drying at $60{ }^{\circ} \mathrm{C}$ for $6 \mathrm{~h}$ and calcining at $1000{ }^{\circ} \mathrm{C}$ for $2 \mathrm{~h}$ in $\mathrm{Ar}$ atmosphere. Finally, the system was infiltrated with PDMS using a vacuum. They found that the composite with thermally treated graphene and OCNT shows $\mathrm{SE} \approx 68 \mathrm{~dB}$ (X-band) for a $1.2 \mathrm{~mm}$ thick sample.

Anooja et al. ${ }^{39}$ made composites using carbon black (CB) and reduced graphene oxide (rGO) in PDMS. They mixed CB (2 wt $\%, 5 \mathrm{wt} \%, 10 \mathrm{wt} \%$, and $17 \mathrm{wt} \%$ ) in $\mathrm{rGO}(5 \mathrm{wt} \%$ and $15 \mathrm{wt} \%)$ solution and sonicated for $30 \mathrm{~min}$. In the abovesonicated solution, PDMS was added and dried overnight. The as-obtained powder was compressed at $200{ }^{\circ} \mathrm{C}$ for $20 \mathrm{~min}$. The prepared composite with rGO $15 \mathrm{wt} \%$ and $\mathrm{CB}$ $17 \mathrm{wt} \%$ showed SE $\sim 28 \mathrm{~dB}$ in the $8-18 \mathrm{GHz}$ range. The composite retained its EM shielding ability even after 1000 bending cycles.
Ou et al. ${ }^{40}$ developed PDMS-based composites using Galinstan (GaInSn) liquid metal. Firstly, they dispersed GaInSn into PDMS by physical mixing. They prepared two different samples with GaInSn:PDMS ratios as $1: 4$ and $1: 8$. The minimum reflection loss (RL) achieved using GaInSn/PDMS composite is $-19.3 \mathrm{~dB}$ at $14.8 \mathrm{GHz}$ at a thickness of $2 \mathrm{~mm}$. They also observed a shift in the RL peak from $14.8 \mathrm{GHz}$ to $9.7 \mathrm{GHz}$ after $30 \%$ elongation.

Lee et $a l^{41}$ prepared a plaid pattern over composite made from bio-PDMS and $\mathrm{BaTiO}_{3}$ (MBPBT). They made the composite using MWCNT and MBPBT. Another solution made from (AgNWs) and $\mathrm{Fe}_{3} \mathrm{O}_{4}$ nanoparticles was a deposit on MBPBT. The two composite films (with MWCNT and Ag NWs) were arranged in two different configurations (parallel and cross configurations). Thus, the prepared composite showed a high EM shielding ability of $11 \mathrm{~dB}$ in cross configuration with $15 \mathrm{wt} \%$ $\mathrm{BaTiO}_{3}$.

Bora et al. ${ }^{42}$ prepared composites using soft magnetic $\mathrm{Gd}_{5} \mathrm{Si}_{4}$ nanoparticles and PDMS. $\mathrm{Gd}_{5} \mathrm{Si}_{4}$ nanoparticles were made from the bulk composite using an arc discharge method followed by ball milling for $2 \mathrm{~h}$. Thus obtained ( $40 \mathrm{wt} \%$ ) nanoparticles were dispersed in PDMS and cured in a vacuum oven at $60^{\circ} \mathrm{C}$ for $6 \mathrm{~h}$. They tested the EM shielding ability of the composite in the Ka-band (12.4-18 GHz). The prepared composite showed SE $69 \mathrm{~dB}$ for a $6 \mathrm{~mm}$ thick sample.

Lin et $a l .{ }^{43}$ fabricated ultrathin nitrogen-doped graphene film by vacuum filtration followed by compression moulding. Thus obtained graphene films were modified using ethylenediamine (EDA). The compressed sheets were spin-coated over the PDMS substrate. For preparing wavy sheet-like structures, the GO sheets were transferred to the pre-molded PDMS substrate. The prepared sample with $6.6 \mu \mathrm{m}$ thickness showed shielding effectiveness of $58.6 \mathrm{~dB}$. They observed that the modified GO sheets showed better shielding effectiveness. 
Li et al. ${ }^{44}$ prepared highly conductive and robust 3D graphene/silver nanowires bi-continuous skeletons for EM shielding. They used the Ag NWs and rGO bi-continuous network (3D bicontinuous network). With low filler concentration, $0.76 \mathrm{wt} \%$ possessed high conductivities of $10.6 \mathrm{~S} \mathrm{~cm}^{-1}$. The sample showed $\mathrm{SE} \sim 34.1 \mathrm{~dB}$; hence, the prepared sample shows excellent thermal conductivity and high compression strength.

Shao et $a .^{45}$ prepared stretchable nanocomposites using $\mathrm{Fe}_{3} \mathrm{O}_{4} / \mathrm{CNT} / \mathrm{PDMS}$ composite film using in situ grown $\mathrm{Fe}_{3} \mathrm{O}_{4}$ over CNT film using the solvothermal method. The obtained $\mathrm{Fe}_{3} \mathrm{O}_{4}$ over CNT film was used to prepare the PDMS composite in planar and wave-like structures (Fig. 9). Firstly, for fabricating the planar composite, the $\mathrm{Fe}_{3} \mathrm{O}_{4} / \mathrm{CNT}$ film was coated over the PDMS substrate, followed by a thin layer coating of PDMS. They also prepared wrinkled films by coating over the pre-stretched film and releasing the stress. They found that with an increasing number of layers, the shielding ability of the composite increases. For 5 layers, they achieved minimum RL $-41.3 \mathrm{~dB}$ at $14 \mathrm{GHz}$ with a bandwidth of $10 \mathrm{~dB}$ (refer to Fig. 10).

$\mathrm{Xu}$ et al. ${ }^{46}$ prepared PDMS-based nanocomposites by direct infiltration into the interconnected rGO network. With the addition of graphene, the mechanical property of the composite increased. For a composite with $3.07 \mathrm{wt} \%$, they achieved high electrical conductivity $\left(\sim 103 \mathrm{~S} \mathrm{~cm}^{-1}\right)$, and the composite showed SE of $54 \mathrm{~dB}$ in X-band for a $2 \mathrm{~mm}$ thick sample.

Li et al. ${ }^{47}$ used CNT film fabricated utilizing a CVD process followed by a solvothermal process to prepare $\mathrm{CNT}-\mathrm{Fe}_{3} \mathrm{O}_{4}$ composites with different concentrations of $\mathrm{Fe}_{3} \mathrm{O}_{4}$. Reduced graphene oxide (rGO) was deposited on the sample using the electrophoretic technique. The prepared $\mathrm{rGO}-\mathrm{CNT}-\mathrm{Fe}_{3} \mathrm{O}_{4}$ composite film was coated with a thin layer of PDMS and cured for $1 \mathrm{~h}$ at $100{ }^{\circ} \mathrm{C}$. The composite film showed minimum RL $-50.5 \mathrm{~dB}$ at $16.3 \mathrm{GHz}$ for four-layer $(t=1.42 \mathrm{~mm})$ composite with the bandwidth of $5.7 \mathrm{GHz}$ with (RL > $10 \mathrm{~dB}$ ).

Zhao et al. ${ }^{48}$ prepared PDMS/rGO/SWCNT (single-walled carbon nanotube) composite through backfilling the $\mathrm{rGO} /$ SWCNT aerogel. The composite showed excellent electrical conductivity of $1.2 \mathrm{~S} \mathrm{~cm}^{-1}$ and EM shielding effectiveness of $31 \mathrm{~dB}$ over X-band with low filler content (0.28 wt\%) for a $2 \mathrm{~mm}$ thick sample.

Mordina et al. ${ }^{49}$ used $\mathrm{Fe}_{3} \mathrm{O}_{4}$ embedded hollow carbon nanofiber (CNF) with PDMS to prepare an efficient EM shield. In a typical process, they used co-electrospinning to prepare nanofiber from polyacrylonitrile/ $\mathrm{FeCl}_{3}$ and poly(methyl methacrylate) followed by carbonization at a higher temperature. The obtained nanofibers were used to fabricate a composite with PDMS. The composite with $25 \mathrm{wt} \%$ carbon nanofiber (consisting of $5 \mathrm{wt} \% \quad \mathrm{Fe}_{3} \mathrm{O}_{4}$ ) gives $\mathrm{RL}=-25 \mathrm{~dB}$ with an absorption bandwidth of $4.33 \mathrm{GHz}$ for a $7.5 \mathrm{~mm}$ thick sample.

\subsection{Others}

Luo et al. ${ }^{10}$ prepared superhydrophobic and multi-responsive polypropylene fabric for EM shielding by depositing $\mathrm{Ag}$ nanoparticles over the ozone-treated fabric followed by spray coating with a mixture of $\mathrm{Fe}_{3} \mathrm{O}_{4}$ and PDMS. The obtained fabric showed excellent conductivity (up to $108.8 \mathrm{~S} \mathrm{~cm}^{-1}$ ) and EM shielding effectiveness $(\mathrm{SE} \sim 56.1 \mathrm{~dB}$ ) in X-band. The material showed excellent stability against sonication, abrasion, and bending tests.

Duan et al. ${ }^{50}$ prepared novel SiOC ceramic by pyrolysis of hyperbranched ferrocene-containing polysiloxane (HBPSO-VF), obtained as a product of reacting polysiloxane (PSO) with 1,1'bis(dimethylvinylsilyl)ferrocene (VF) at $160{ }^{\circ} \mathrm{C}$ for $2 \mathrm{~h}$. The

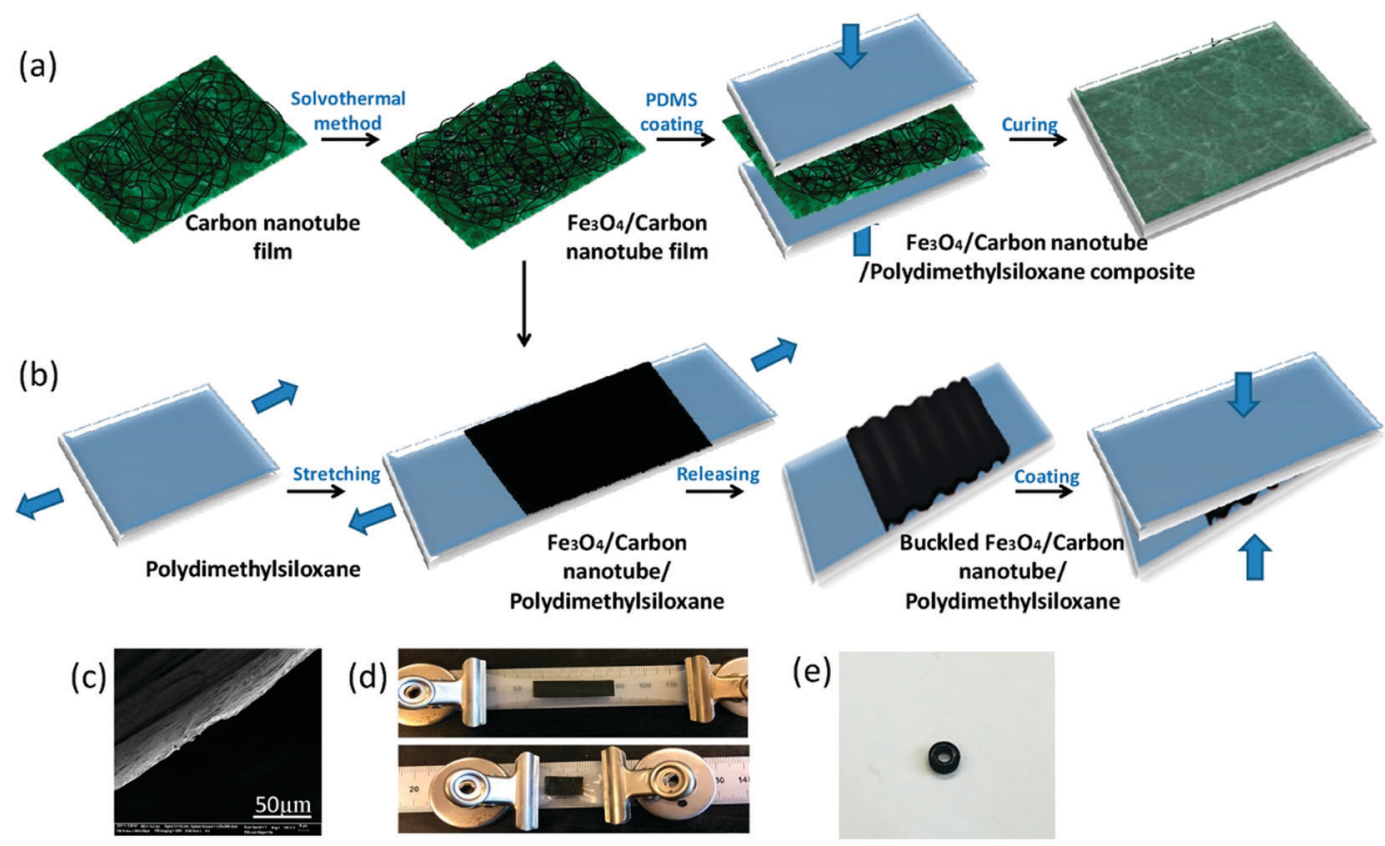

Fig. 9 (a and b) Schematic illustration of the fabrication of $\mathrm{Fe}_{3} \mathrm{O}_{4} /$ carbon nanotube/poly(dimethylsiloxane) composites. (c) Cross-section of the carbon nanotube film. (d) Stretching-releasing process. (e) Test specimen for EM shielding test. [Reprinted (adapted) with permission from (ACS Appl. Nano Mater., 2018, 1(5), 2227-2236). Copyright (2018) American Chemical Society.] 
(a)

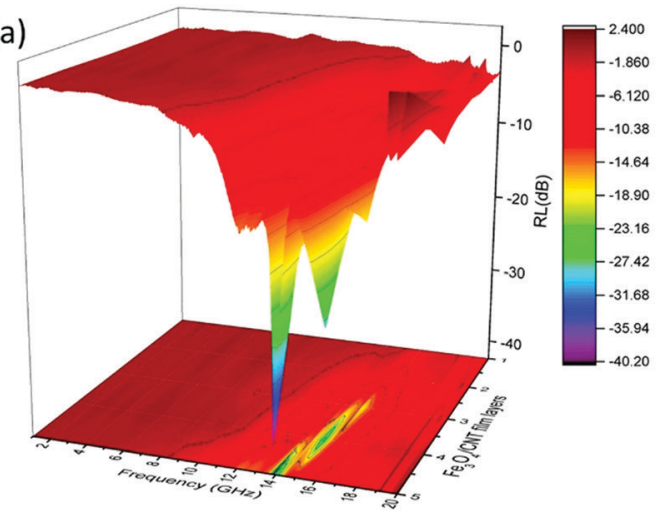

(b)

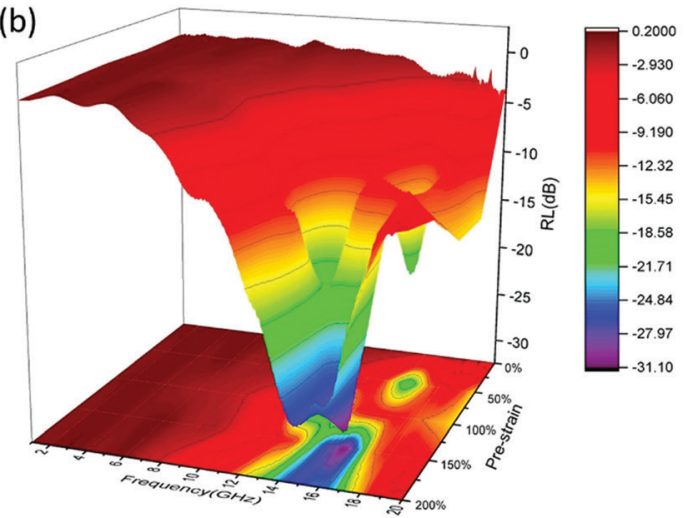

(c)

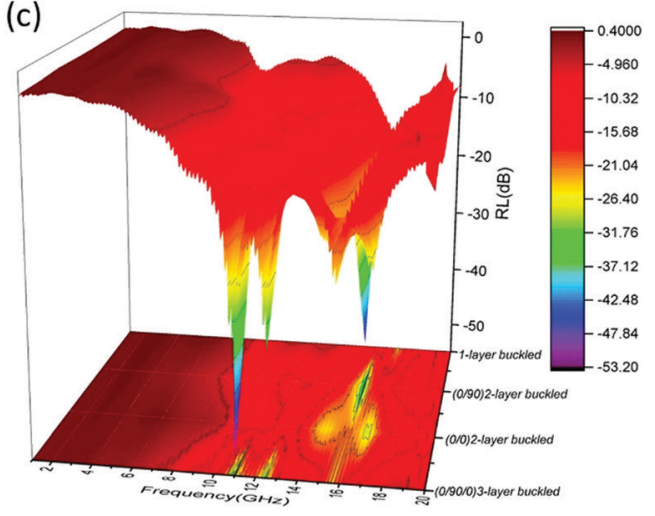

(d)

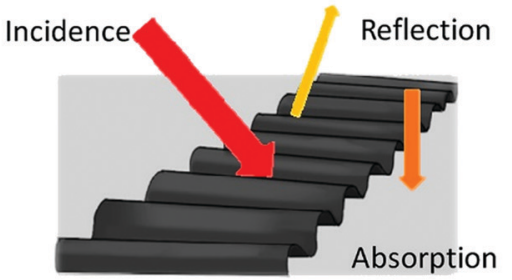

Fig. 10 (a) RL of multilayer flat $\mathrm{Fe}_{3} \mathrm{O}_{4} /$ carbon nanotube/poly(dimethylsiloxane) composites. (b) $\mathrm{RL}$ of one-layer buckled Fe $\mathrm{O}_{4} / \mathrm{carbon}$ nanotube/ poly(dimethylsiloxane) composites for different pre-strains. (c) RL of multilayer $100 \%$ pre-strain buckled $\mathrm{Fe}_{3} \mathrm{O}_{4} /$ carbon nanotube/poly(dimethylsiloxane) composites. (d) Schematic illustration of EM-wave interaction with a buckled $\mathrm{Fe}_{3} \mathrm{O}_{4} /$ carbon nanotube/poly(dimethylsiloxane) composite. [Reprinted (adapted) with permission from (ACS Appl. Nano Mater., 2018, 1(5), 2227-2236). Copyright (2018) American Chemical Society].

obtained product was ball milled for $2 \mathrm{~h}$ and pellets were formed by cold press. The obtained pellets were pyrolyzed at $900{ }^{\circ} \mathrm{C}$ in the $\mathrm{Ar}$ atmosphere. The obtained ceramic was annealed at a different temperature from $1000-1450{ }^{\circ} \mathrm{C}$ in the $\mathrm{Ar}$ atmosphere. The composite with $1 \mathrm{wt} \% \mathrm{Fe}$ and thickness of $2.5 \mathrm{~mm}$ calcined at $1100{ }^{\circ} \mathrm{C}$ showed $\mathrm{RC} \sim 36 \mathrm{~dB}$.

Bayat et al. ${ }^{51}$ studied the effect of PDMS coating on the EMI shielding ability of the $\mathrm{Fe}_{3} \mathrm{O}_{4}$ coated carbon fiber. They used electrospinning to fabricate polyacrylonitrile (PAN) based fiber filled with $\mathrm{Fe}_{3} \mathrm{O}_{4}$ nanoparticles in a typical process. The obtained fibers were carbonized at $900{ }^{\circ} \mathrm{C}$. Thus obtained samples were coated with PDMS. They found no significant effect of PDMS coating on the EM shielding ability of the composite (SE $\sim 23 \mathrm{~dB}$ ) for $t=0.25 \mathrm{~mm}$.

\section{Perspective}

The journey of PDMS-based composites from bench to translational research for EMI shielding applications is reviewed here in detail. In the last decade, various forms of PDMS-based nanocomposites for the targeted applications have been designed to cater to different applications like flexible gaskets, reinforced sheets, encapsulating critical biomedical devices, contact lenses, etc. In addition to making various components, PDMS-based coatings over porous structures obtained by carbonization of various foams resulting in foam-like structures have also been attempted. Since, PDMS is transparent to EM waves, various functional nanoparticles have been added to render the composites with key attributes, such as conducting, magnetic, and/or dielectric properties. However, the presence of sulphur inhibits the catalytic activity of Pt-based catalysts; therefore, in most cases, researchers have used tinbased catalysts for crosslinking, which is key to realizing the exceptional properties that PDMS has to offer. ${ }^{52}$ This further leads to preparing composites using a hydrosilylation crosslinking mechanism, which is more environmentally friendly. Recently, researchers have also explored click chemistry to enhance the crosslinking in PDMS.

From the current state-of-the-art literature, it is well understood that PDMS-based foams are the most popular choice for designing lightweight EMI shielding materials. Among the various particle systems, $2 \mathrm{D}$ nanomaterials (like $\mathrm{MoS}_{2}, \mathrm{WS}_{2}$, and others) need to be explored as the huge specific surface area of these 2D nanomaterials can help shield through multiple internal reflections/scattering. In addition, nanoporous materials like metal-organic frameworks (MOF) and covalent organic frameworks (COF), when blended with PDMS, offer a range of functional particles that can be further explored for EMI shielding materials. Due to their high thermal stability, these polymer composites can be used to shield electronic devices operating at 
high temperatures and, in addition, can also dissipate heat, thereby protecting the precise electronics. More research should be focused on enhancing the shelf life of these composites by incorporating functional particles that can block both UV as well as EMI.

The use of PDMS based nanocomposites is more favourable as PDMS is biocompatible and hence, less harmful to the environment. Such nanocomposite nanocomposites can find their potential use in the healthcare industry. Also, owing to their high thermal stability, these nanocomposites can find their application in devices operating at higher temperatures. Also, these composites or coatings are mostly in demand in moisture sensitive equipment as PDMS shows very high hydrophobicity.

This review article highlights the journey of PDMS-based composites designed for EMI shielding applications. Various case studies have been presented to help guide the researchers working in this area from both industry and academia. Given the surge in the operating frequencies (higher $\mathrm{GHz}$ ), more research should focus on PDMS based composites with hybrid and/or core-shell structures, multi-layered architectures, and both rigid/soft foam-like structures.

\section{Conflicts of interest}

There are no conflicts to declare.

\section{References}

1 J. Pomposo, J. Rodriguez and H. Grande, Polypyrrole-based conducting hot melt adhesives for EMI shielding applications, Synth. Met., 1999, 104(2), 107-111.

2 R. Rohini and S. Bose, Electrodeposited carbon fiber and epoxy based sandwich architectures suppress electromagnetic radiation by absorption, Composites, Part B, 2019, 161, 578-585.

3 M. Sharma, M. P. Singh, C. Srivastava, G. Madras and S. Bose, Poly(vinylidene fluoride)-Based Flexible and Lightweight Materials for Attenuating Microwave Radiations, ACS Appl. Mater. Interfaces, 2014, 6(23), 21151-21160.

4 S. P. Pawar, D. A. Marathe, K. Pattabhi and S. Bose, Electromagnetic interference shielding through MWNT grafted $\mathrm{Fe}_{3} \mathrm{O}_{4}$ nanoparticles in PC/SAN blends, J. Mater. Chem. A, 2015, 3(2), 656-669.

5 R. Rohini and S. Bose, Electromagnetic Interference Shielding Materials Derived from Gelation of Multiwall Carbon Nanotubes in Polystyrene/Poly(methyl methacrylate) Blends, ACS Appl. Mater. Interfaces, 2014, 6(14), 11302-11310.

6 S. P. Pawar, S. Biswas, G. P. Kar and S. Bose, High frequency millimetre wave absorbers derived from polymeric nanocomposites, Polymer, 2016, 84, 398-419.

7 M. H. Al-Saleh, W. H. Saadeh and U. Sundararaj, EMI shielding effectiveness of carbon based nanostructured polymeric materials: A comparative study, Carbon, 2013, 60, 146-156.

8 C. L. Bliss, J. N. McMullin and C. J. Backhouse, Integrated wavelength-selective optical waveguides for microfluidicbased laser-induced fluorescence detection, Lab Chip, 2008, 8(1), 143-151.

9 C. Cao, M. Ge, J. Huang, S. Li, S. Deng, S. Zhang, Z. Chen, K. Zhang, S. S. Al-Deyab and Y. Lai, Robust fluorine-free superhydrophobic PDMS-ormosil@fabrics for highly effective self-cleaning and efficient oil-water separation, J. Mater. Chem. A, 2016, 4(31), 12179-12187.

10 J. Luo, L. Huo, L. Wang, X. Huang, J. Li, Z. Guo, Q. Gao, M. Hu, H. Xue and J. Gao, Superhydrophobic and multiresponsive fabric composite with excellent electro-photothermal effect and electromagnetic interference shielding performance, Chem. Eng. J., 2019, 123537.

11 Y. He, Y. Ming, W. Li, Y. Li, M. Wu, J. Song, X. Li and H. Liu, Highly stable and flexible pressure sensors with modified multi-walled carbon nanotube/polymer composites for human monitoring, Sensors, 2018, 18(5), 1338.

12 D. He, Y. Xie, X. Wang and Z. Zhang, Significantly Enhanced Electromechanical Performance of PDMS Crosslinked PVDF Hybrids, Polymers, 2018, 10(7), 714.

13 Y. Wu, X. Sun, W. Wu, X. Liu, X. Lin, X. Shen, Z. Wang, R. K. Y. Li, Z. Yang, K.-T. Lau and J.-K. Kim, Graphene foam/ carbon nanotube/poly(dimethyl siloxane) composites as excellent sound absorber, Composites, Part A, 2017, 102, 391-399.

14 M. Chen, L. Zhang, S. Duan, S. Jing, H. Jiang, M. Luo and C. Li, Highly conductive and flexible polymer composites with improved mechanical and electromagnetic interference shielding performances, Nanoscale, 2014, 6(7), 3796-3803.

15 R. R. Mishra and A. K. Sharma, Microwave-material interaction phenomena: Heating mechanisms, challenges and opportunities in material processing, Composites, Part A, 2016, 81, 78-97.

16 K. L. Ngai, A. K. Jonscher and C. T. White, On the origin of the universal dielectric response in condensed matter, Nature, 1979, 277(5693), 185-189.

17 H. Zhang and A. K. Datta, Microwave Power Absorption in Single - and Multiple - Item Foods, Food Bioprod. Process., 2003, 81(3), 257-265.

18 M. Sparks, R. Loudon and C. Kittel, Ferromagnetic relaxation. I. Theory of the relaxation of the uniform precession and the degenerate spectrum in insulators at low temperatures, Phys. Rev., 1961, $122(3), 791$.

19 D. M. Pozar, Microwave engineering, John Wiley \& Sons, 2009.

20 A. J. Moulson and J. M. Herbert, Electroceramics: materials, properties, applications, John Wiley \& Sons, 2003.

21 J. L. Snoek, Dispersion and absorption in magnetic ferrites at frequencies above one Mc/s, Physica, 1948, 14(4), 207-217.

22 D. Ao, Y. Tang, X. Xu, X. Xiang, J. Yu, S. Li and X. Zu, Highly Conductive PDMS Composite Mechanically Enhanced with 
3D-Graphene Network for High-Performance EMI Shielding Application, Nanomaterials, 2020, 10(4), 768.

23 X. Wu, B. Han, H.-B. Zhang, X. Xie, T. Tu, Y. Zhang, Y. Dai, R. Yang and Z.-Z. Yu, Compressible, durable and conductive polydimethylsiloxane-coated MXene foams for highperformance electromagnetic interference shielding, Chem. Eng. J., 2020, 381, 122622.

24 V.-T. Nguyen, B. K. Min, Y. Yi, S. J. Kim and C.-G. Choi, MXene $\left(\mathrm{Ti}_{3} \mathrm{C}_{2} \mathrm{TX}\right)$ /graphene/PDMS composites for multifunctional broadband electromagnetic interference shielding skins, Chem. Eng. J., 2020, 393, 124608.

25 L. Kong, X. Yin, H. Xu, X. Yuan, T. Wang, Z. Xu, J. Huang, R. Yang and H. Fan, Powerful absorbing and lightweight electromagnetic shielding CNTs/RGO composite, Carbon, 2019, 145, 61-66.

26 C. Yu, S. Zhu, C. Xing, X. Pan, X. Zuo, J. Liu, M. Chen, L. Liu, G. Tao and Q. Li, Fe nanoparticles and CNTs co-decorated porous carbon/graphene foam composite for excellent electromagnetic interference shielding performance, J. Alloys Compd., 2020, 820, 153108.

27 D. Lu, Z. Mo, B. Liang, L. Yang, Z. He, H. Zhu, Z. Tang and $\mathrm{X}$. Gui, Flexible, lightweight carbon nanotube sponges and composites for high-performance electromagnetic interference shielding, Carbon, 2018, 133, 457-463.

28 H. Li, L. Jing, Z. L. Ngoh, R. Y. Tay, J. Lin, H. Wang, S. H. Tsang and E. H. T. Teo, Engineering of High-Density Thin-Layer Graphite Foam-Based Composite Architectures with Superior Compressibility and Excellent Electromagnetic Interference Shielding Performance, ACS Appl. Mater. Interfaces, 2018, 10(48), 41707-41716.

29 L. Kong, X. Yin, M. Han, X. Yuan, Z. Hou, F. Ye, L. Zhang, L. Cheng, Z. Xu and J. Huang, Macroscopic bioinspired graphene sponge modified with in-situ grown carbon nanowires and its electromagnetic properties, Carbon, 2017, 111, 94-102.

30 C. Song, X. Yin, M. Han, X. Li, Z. Hou, L. Zhang and L. Cheng, Three-dimensional reduced graphene oxide foam modified with $\mathrm{ZnO}$ nanowires for enhanced microwave absorption properties, Carbon, 2017, 116, 50-58.

31 D. Han, Y.-H. Zhao, S.-L. Bai and W. C. Ping, High shielding effectiveness of multilayer graphene oxide aerogel film/ polymer composites, RSC Adv., 2016, 6(95), 92168-92174.

32 Z. Chen, C. Xu, C. Ma, W. Ren and H.-M. Cheng, Lightweight and Flexible Graphene Foam Composites for HighPerformance Electromagnetic Interference Shielding, Adv. Mater., 2013, 25(9), 1296-1300.

33 Y. Wang, W. Wang, Q. Qi, N. Xu and D. Yu, Layer-by-layer assembly of PDMS-coated nickel ferrite/multiwalled carbon nanotubes/cotton fabrics for robust and durable electromagnetic interference shielding, Cellulose, 2020, 27(5), 2829-2845.

34 J. Luo, L. Wang, X. Huang, B. Li, Z. Guo, X. Song, L. Lin, L.-C. Tang, H. Xue and J. Gao, Mechanically Durable, Highly Conductive, and Anticorrosive Composite Fabrics with Excellent Self-Cleaning Performance for High-Efficiency Electromagnetic Interference Shielding, ACS Appl. Mater. Interfaces, 2019, 11(11), 10883-10894.
35 J. Zheng, X. He, Y. Li, B. Zhao, F. Ye, C. Gao, M. Li and X. Li, E, S., Viscoelastic and Magnetically Aligned Flaky Fe-Based Magnetorheological Elastomer Film for Wide-Bandwidth Electromagnetic Wave Absorption, Ind. Eng. Chem. Res., 2020, 59(8), 3425-3437.

36 H. Nallabothula, Y. Bhattacharjee, L. Samantara and S. Bose, Processing-Mediated Different States of Dispersion of Multiwalled Carbon Nanotubes in PDMS Nanocomposites Influence EMI Shielding Performance, ACS Omega, 2019, 4(1), 1781-1790.

37 J. Li, Y.-J. Tan, Y.-F. Chen, H. Wu, S. Guo and M. Wang, Constructing multiple interfaces in polydimethylsiloxane/ multi-walled carbon nanotubes nanocomposites by the incorporation of cotton fibers for high-performance electromagnetic interference shielding and mechanical enhancement, Appl. Surf. Sci., 2019, 466, 657-665.

38 S. Zhu, C. Xing, F. Wu, X. Zuo, Y. Zhang, C. Yu, M. Chen, W. Li, Q. Li and L. Liu, Cake-like flexible carbon nanotubes/ graphene composite prepared via a facile method for highperformance electromagnetic interference shielding, Carbon, 2019, 145, 259-265.

39 J. B. Anooja, K. S. Dijith, K. P. Surendran and G. Subodh, A simple strategy for flexible electromagnetic interference shielding: Hybrid rGO@CB-Reinforced polydimethylsiloxane, J. Alloys Compd., 2019, 807, 151678.

40 M. Ou, H. Liu, X. Chen, S. Chu and G. Chu, Tunable electromagnetic wave-absorbing capability achieved in liquid-metal-based nanocomposite, Appl. Phys. Express, 2019, $12(4), 045005$.

41 D. W. Lee, J. Park, B. J. Kim, H. Kim, C. Choi, R. H. Baughman, S. J. Kim and Y. T. Kim, Enhancement of electromagnetic interference shielding effectiveness with alignment of spinnable multiwalled carbon nanotubes, Carbon, 2019, 142, 528-534.

42 P. J. Bora, S. M. Harstad, S. Gupta, V. K. Pecharsky, K. J. Vinoy, P. C. Ramamurthy and R. L. Hadimani, Gadolinium silicide $\left(\mathrm{Gd}_{5} \mathrm{Si}_{4}\right)$ nanoparticles for tuneable broad band microwave absorption, Mater. Res. Express, 2019, 6(5), 055053.

43 S. Lin, S. Ju, G. Shi, J. Zhang, Y. He and D. Jiang, Ultrathin nitrogen-doping graphene films for flexible and stretchable EMI shielding materials, J. Mater. Sci., 2019, 54(9), 7165-7179.

44 Y. Li, C. Li, S. Zhao, J. Cui, G. Zhang, A. Gao and Y. Yan, Facile fabrication of highly conductive and robust threedimensional graphene/silver nanowires bicontinuous skeletons for electromagnetic interference shielding silicone rubber nanocomposites, Composites, Part A, 2019, 119, 101-110.

45 Y. Shao, J. Li, W. Lu, J. Q. Xiao, Y. Qiu and T.-W. Chou, Microbuckling-Enhanced Electromagnetic-Wave-Absorbing Capability of a Stretchable $\mathrm{Fe}_{3} \mathrm{O}_{4}$ /Carbon Nanotube/ Poly(dimethylsiloxane) Composite Film, ACS Appl. Nano Mater., 2018, 1(5), 2227-2236.

46 F. Xu, R. Chen, Z. Lin, Y. Qin, Y. Yuan, Y. Li, X. Zhao, M. Yang, X. Sun, S. Wang, Q. Peng, Y. Li and X. He, Superflexible Interconnected Graphene Network Nanocomposites 
for High-Performance Electromagnetic Interference Shielding, ACS Omega, 2018, 3(3), 3599-3607.

$47 \mathrm{~J}$. Li, Y. Xie, W. Lu and T.-W. Chou, Flexible electromagnetic wave absorbing composite based on 3D rGO-CNT- $-\mathrm{Fe}_{3} \mathrm{O}_{4}$ ternary films, Carbon, 2018, 129, 76-84.

48 S. Zhao, Y. Yan, A. Gao, S. Zhao, J. Cui and G. Zhang, Flexible Polydimethylsilane Nanocomposites Enhanced with a Three-Dimensional Graphene/Carbon Nanotube Bicontinuous Framework for High-Performance Electromagnetic Interference Shielding, ACS Appl. Mater. Interfaces, 2018, 10(31), 26723-26732.

49 B. Mordina, R. Kumar, R. K. Tiwari, D. K. Setua and A. Sharma, Fe3O4 Nanoparticles Embedded Hollow Mesoporous Carbon Nanofibers and Polydimethylsiloxane-Based
Nanocomposites as Efficient Microwave Absorber, J. Phys. Chem. C, 2017, 121(14), 7810-7820.

50 W. Duan, X. Yin, C. Luo, J. Kong, F. Ye and H. Pan, Microwave-absorption properties of SiOC ceramics derived from novel hyperbranched ferrocene-containing polysiloxane, J. Eur. Ceram. Soc., 2017, 37(5), 2021-2030.

51 M. Bayat, H. Yang, F. K. Ko, D. Michelson and A. Mei, Electromagnetic interference shielding effectiveness of hybrid multifunctional $\mathrm{Fe}_{3} \mathrm{O}_{4}$ /carbon nanofiber composite, Polymer, 2014, 55(3), 936-943.

52 V. Srinivas, Y. Nakajima, W. Ando, K. Sato and S. J. C. S. Shimada, (Salicylaldiminato)Ni(II)-catalysts for hydrosilylation of olefins, Catal. Sci. Technol., 2015, 5(4), 2081-2084. 